\title{
IMPLEMETASI GREENFOOT 3.0.4 UNTUK MEMBANGUN APLIKASI PENGUCAPAN BAHASA INGGRIS PADA ARROBBANY COURSE
}

\author{
Wire Bagye1, Yuliana², \\ Program Studi Teknik Informatika \\ Sekolah Tinggi Manajemen Informatika dan Komputer (STMIK) Lombok \\ Jln. Basuki Rahmat No. 105 Praya Lombok Tengah \\ ${ }^{1}$ wirestmik@gmail.com, ${ }^{2}$ youlieasaqina@gmail.com,
}

\begin{abstract}
Arrobbany English Courses is an institutions which have only a single manager and tutor in guiding 67 students consisting of students from primary and secondary school level. In teaching and learning tutor often have difficulty in establishing a nice environment for some students would rather play than on learning. This causes the limited learning topic that can be delivered to students tutor each meeting. Therefore, it needs the right solution and does not incur costs to add a tutor or a native speaker, using a medium of learning. One of the media to learn the most widely used today is the computer as a proven way to speed up the delivery of learning topic and increase student interest.

In this study Aplikasi Pembelajaran Bahasa Ingris is built to help tutor show the right pronoun to the students. Sound of pronoun will sounded when the picture clicked. There are seven learning menus in this application. Application development using Greenfoot with object-oriented programming concepts. Method development using SDLC, UML design and testing method using the Black-box testing. English Language Learning application is compiled into .jar extensions which can be run on the Windows operating system which have been installed JDK.

Based on testing to 23 students indicates that the Aplikasi Pembelajaran Bahasa Ingris is exciting, produce the proper sound, and can replace the native speaker. The result of the assessment shows that average percentage are more than $82 \%$.
\end{abstract}

Kata Kunci : English, Learning Media, Greenfoot, Java Programming Language

\section{Abstrak}

Lembaga Kursus Bahasa Inggris Arrobbany memiliki pengelola dan tutor tunggal dalam membimbing 67 siswa yang terdiri dari siswa dari tingkat SD dan SLTP. Pada kegiatan belajar dan mengajar tutor seringkali mengalami kesulitan dalam membangun suasana yang kondusif karena beberapa siswa lebih suka bermain dari pada belajar. Hal ini menyebabkan terbatasnya materi yang dapat disampaikan tutor kepada siswa setiap pertemuan. Oleh karena itu dibutuhkan solusi tepat dan tidak mendatangkan biaya dengan menambah tutor atau native speaker, yaitu dengan menggunakan media belajar. Salah satu media belajar yang paling banyak digunakan saat ini adalah komputer karena terbukti dapat mempercepat proses penyampaian materi dan meningkatkan minat belajar siswa.

Pada penelitian ini dibangun Aplikasi Pembelajaran Bahasa Inggris untuk membantu pembelajaran pronoun yang dapat mengeluarkan suara apabila diklik dengan tujuh menu belajar. Pengembangan menggunakan Aplikasi Greenfoot dengan konsep pemrograman berorientasi objek. Metode pengembangan menggunakan SDLC, metode perancangan UML dan pengujian menggunakan Black-box testing. Aplikasi Pembelajaran Bahasa Inggris dikompilasi ke ekstensi .jar yang dapat dijalankan pada sistem operasi Windows yang terinstal JDK.

Berdasarkan pengujian pada 23 siswa, menunjukkan bahwa aplikasi pembelajaran bahasa inggris ini menarik, menghasilkan suara yang tepat, dan dapat menggantikan native speaker. Hal ini terlihat pada aspek penilaian menunjukkan rata-rata persentase lebih dari $82 \%$.

Keywords : English, Learning Media, Greenfoot, Java Programming Language 


\section{Pendahuluan}

\subsection{Latar Belakang}

Bahasa Inggris pada saat ini merupakan kebutuhan yang sangat penting dalam segala bidang karena bahasa Inggris telah menjadi bahasa Internasional. Bahasa Inggris digunakan oleh banyak Negara yang perlu diajarkan sejak dini sehingga membentuk kebiasaan anak dari penguasaan kosa kata sampai dengan cara membaca atau pelafalan. Namun masih banyak siswa yang kurang meminati pelajaran bahasa inggris.

Salah satu cara untuk meningkatkan perhatian dan keterlibatan siswa dalam aktivitas belajar diperlukan adanya alat pendukung berupa alat-alat bantu visual, mainan, boneka ataupun objek-objek lain yang berwarna-warni, yang sesuai pembelajaran. Pengajaran dan pembelajaran bahasa Inggris berbasis multimedia dapat menjadi alat bantu pembelajaran interaktif yang dapat meningkatkan minat belajar anak. Sehingga Rancang Bangun Aplikasi Pembelajaran Bahasa Inggris berbasis komputer perlu dikembangkan.

Keterbatasan waktu dan biaya untuk menghadirkan native speaker merupakan salah satu faktor penghambat dalam proses belajar bahasa Inggris[3]. Diperlukan aplikasi yang mampu melatih pengguna dalam belajar bahasa inggris mengucapkan kata dan kalimat sehingga dapat mewakili peran tenaga pengajar dalam belajar pengucapan. Peran pengajar akan dialihkan pada fungsi evaluasi pengucapan bahasa inggris.

\section{Tinjauan pustaka}

Penelitian yang dilakukan oleh Dewi Ghea P. F. (2012) Program Study Teknik Informatika Universitas Negeri Yogyakarta dengan judul Pengembangan Game Edukasi Pengenalan Nama Hewan Dalam Bahasa Inggris Sebagai Media Pembelajaran Siswa SD Berbasis Macromedia Flash. Pada penelitian ini mengangkat masalah bagaimana pengembangan game edukasi pengenalan nama hewan dalam bahasa Inggris berbasis Macromedia Flash sebagai media pembelajaran untuk meningkatkan hasil belajar siswa. Hasil dari penelitian ini yaitu media pembelajaran game edukasi animal pengenalan nama hewan dalam bahasa Inggris untuk kelas IV SD. Dengan hasil uji kelayakan ahli media pada rata-rata 4,32 termasuk dalam kategori sangat layak. Ahli materi pada rata-rata 4,59, termasuk dalam kategori sangat layak, dan hasil uji coba siswa ada pada rata-rata 3,07 termasuk dalam kategori baik.
Penelitian yang dilakukan oleh Ryandi Surya Gautama (2013) Program Study Teknik Informatika Universitas STMIK Global Informatika Multi Data Palembang dengan judul Rancang Bangun Aplikasi Pembelajaran Bahasa Inggris Berbasis Multimedia Pada Bimbel Excellence. Pada penelitian ini mengangkat masalah bagaimana membangun aplikasi pembelajaran bahasa Inggris berbasis multimedia pada Bimbel Excellence. Hasil dari penelitian ini yaitu sebuah aplikasi pembelajaran bahasa Inggris berbasis multimedia sebagai alat bantu pembelajaran interaktif yang dapat meningkatkan minat belajar pengguna.

Penelitian yang dilakukan oleh Yessy Kurniasari (2013) Program Study Teknik Sistem Komputer Universitas Diponegoro dengan judul Perancangan Permainan Mengasah Daya Ingat "Memory Training" Menggunakan Greenfoot. Pada penelitian ini mengangkat masalah bagaimana membangun game untuk mengasah daya ingat anak usia 7 sampai 12 tahun. Hasil dari penelitian ini adalah sebuah aplikasi game "Memory Training" menggunakan software Greenfoot dengan bahasa pemrograman java dengan hasil penilaian tampilan, pengoperasian, ketepatan fungsi dan ketertarikan anak rata rata $96 \%$.

Penelitian oleh Nugroho Septyanto Jati (2015) Program Study Informatika Universitas Muhammadiyah Surakarta dengan judul Aplikasi Pembelajaran Bahasa Inggris untuk Anak SD Menggunakan Construct 2. Pada penelitian ini mengangkat masalah bagaimana membangun media pembelajaran yang dapat menarik siswa agar lebih tertarik dalam belajar Bahasa Inggris. Hasil dari penelitian ini adalah berupa Aplikasi pembelajaran yang menarik Aplikasi ini mudah digunakan bagi siswa SD dengan hasil Prosentase Interpretasi guru sebesar $100 \%$, dan Prosentase Interpretasi siswa sebesar 89,4\%.

Penelitian oleh Galih Dadag Priambodho (2016) Program Study Teknik Informatika Universitas Nusantara PGRI Kediri dengan judul Aplikasi Game Edukasi Pelafalan Huruf Alphabet Berbasis Android. Pada penelitian ini mengangkat masalah bagaimana membuat game edukasi pelafalan huruf alphabet yang dapat meningkatkan minat belajar anak. Hasil dari penelitian ini adalah sebuah aplikasi game edukasi menggunakan software App Inventor yang dapat dijalankan pada smartphone bersistem operasi android. Game mobile ini merupakan game edukasi pelafalan huruf alphabet yang sesuai dengan anak usia 3 sampai 6 tahun yang bisa mengajarkan anak cara melafal huruf alphabet secara baik. 


\section{Green Foot}

Greenfoot adalah perangkat lunak yang didesain untuk pemula agar dapat terbiasa dengan Pemrograman Berorientasi Objek (Object-Oriented Programming), yang mendukung pengembangan aplikasi bergambar dengan memakai bahasa pemrograman Java. Greenfoot didesain dan telah diimplentasikan di Universitas Kent, Inggris dan Universitas Deakin, Melbourne - Australia.

Greenfoot menyediakan empat kelas penting yang perlu anda ketahui: World, Actor, Greenfoot Image dan Greenfoot. Kelas World dan Actor sudah kita lihat sejauh ini di jendela aplikasi sebagai kelas induk (superclass). Kelas Greenfoot Image digunakan ketika berkaitan dengan gambar, dan kelas Greenfoot menyediakan akses ke framework Greenfoot itu sendiri.

Terdapat 3 versi yang tersedia: untuk Windows, untuk MacOS X, dan untuk sistem operasi yang lain. Diperlukan Java 5(JDK) versi 1.5 atau yang terbaru untuk menjalankan Greenfoot. Tidak direkomendasikan meggunakan Java versi "JRE" (Java Runtime Environment) karena JRE sendiri tidaklah cukup, Anda membutuhkan Java versi "JDK"Uava Development Kit).

\section{Metodologi penelitian}

\subsection{Metode pengumpulan Data}

a. Observasi cara pembelajaran yang terapkan di lembaga kursus Arrobbany.

b. Wawancara metode belajar dan kendala tutordan peserta kursu.

c. Studi Pustaka untuk mendapatkan teori dan informasi yang berhubungan dengan topik penelitian ini. Informasi akan dicari melalui buku-buku, internet, dan hasil penelitian maupun karya ilmiah.

\subsection{Metode Perancangan Sistem}

Untuk menunjukkan prosedur sistem yang akan dibangun secara logika maka peneliti menggambarkanya dalam sebuah flowcart berikut.

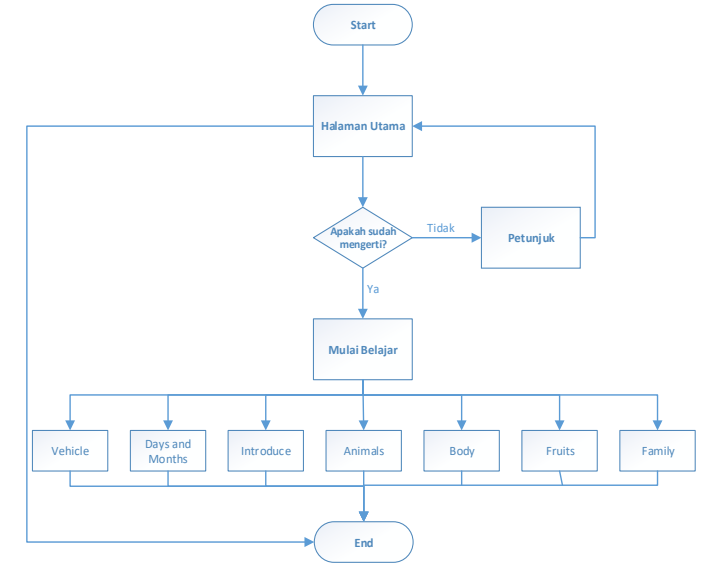

Gambar 3.1. Flowchart sistem yang akan dibangun

\subsection{Perancangan Proses}

Pembuatan perancangan desain menggunakan UML, yang menggunakan konsep berorientasi objek.

\section{Use Case Diagram}

Use case diagram mendeskripsikan interaksi aktor atau pengguna dengan Aplikasi Pembelajaran Bahasa Inggris yang akan dibuat. Perancangan proses dengan use case diagram dalam permainan ini dapat dilihat pada gambar berikut.

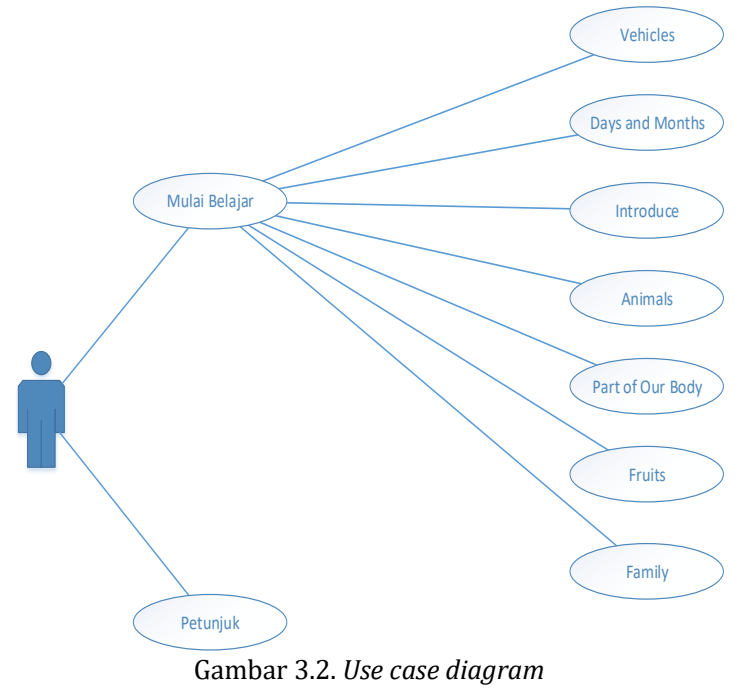

\section{Activity Diagram}

Activity diagram digunakan untuk menggambarkan alur aktivitas dari tiap use case. Activity diagram tidak membahas detail urutan proses, namun hanya memberikan gambaran umum bagaimana urutan prosesnya. Ada beberapa activity atau aktivitas pada aplikasi ini, diantaranya : 
1) Activity diagram menampilkan Menu Utama

Menu utama adalah menu yang ada pada halaman utama aplikasi pembelajaran bahasa inggris. Aktivitas pertama user dimulai dengan memilih salah satu dari dua menu yang ada pada halaman utama yaitu menu mulai belajar dan menu petunjuk.

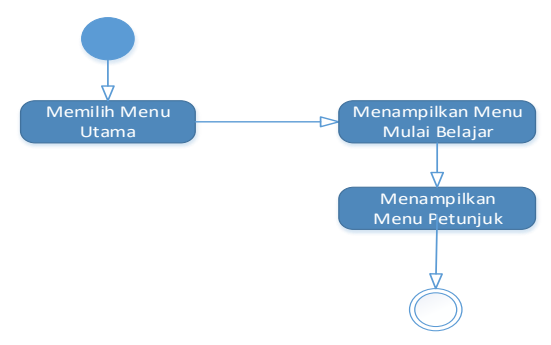

Gambar 3.3. Activity diagram menu utama

2) Activity diagram menampilkan menu Mulai Belajar

Menu mulai belajar berfungsi untuk menampilkan daftar menu belajar yang dapat dipilih dan digunakan oleh user. Terdapat tujuh menu belajar pada daftar menu antara lain adalah menu Vehicle, Days and Months, Introduce, Animals, Part of Our Body, Fruits dan Family

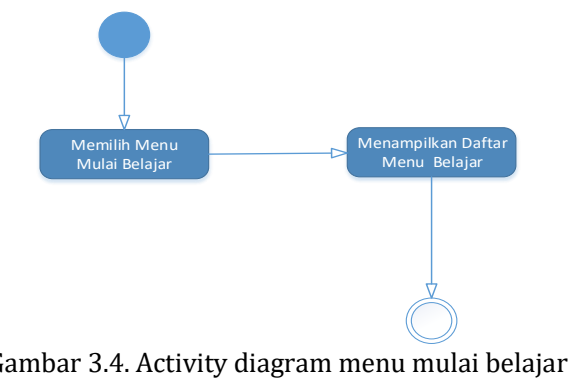

3) Activity diagram menampilkan menu Petunjuk

Menu petunjuk berfungsi untuk menampilkan petunjuk penggunaan aplikasi dan menjelaskan fungsi tombol yang ada pada aplikasi. Untuk mengakses menu petunjuk user mengklik menu petunjuk pada halaman utama aplikasi.

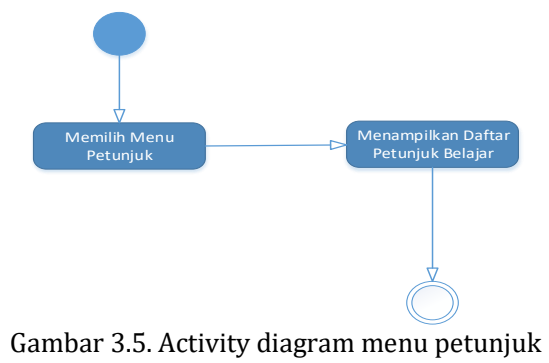

4) Activity diagram menampilkan menu Vehicles

Menu vehicles adalah menu belajar dengan materi belajar nama - nama alat transportasi.
User dapat menggunakan menu ini dengan cara mengkilk menu vehicle pada daftar menu belajar.

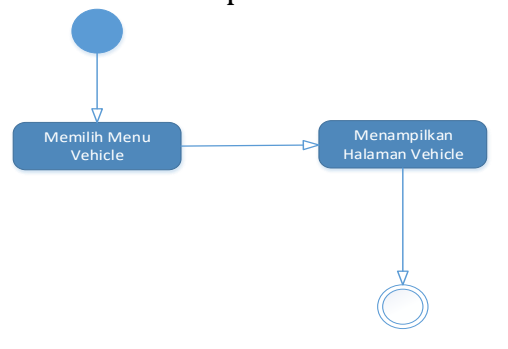

Gambar 3.6. Activity diagram menu vehicle

\section{Diagram Sequence}

Diagram ini menggambarkan fungsionalitas dari masing-masing use case dan interaksi yang terjadi antar objek dalam sistem.

1) Diagram sequence pada menu Mulai Belajar

Sequence menu mulai belajar diawali dengan membuka aplikasi kemudian mengklik tombol Run pada aplikasi. Untuk menggunakan langsung aplikasi, maka user memilih menu Mulai Belajar dan akan ditampilkan daftar menu belajar yang dapat digunakan oleh user. Setelah selesai menggunakan menu belajar user dapat kembali kehalaman utama untuk mengakhiri aplikasi.

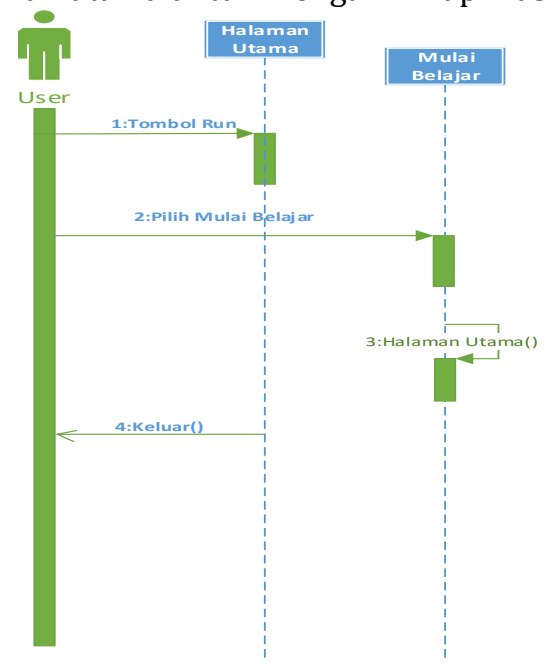

Gambar 3.7. Sequence diagram mulai belajar

2) Diagram sequence pada menu Petunjuk

Apabila user belum paham dengan cara menggunakan aplikasi, maka user dapat mempelajari langkah penggunaan aplikasi pada menu Petunjuk. Menu Petunjuk dapat dijalankan dari halaman utama dengan cara mengklik menu Petunjuk dan akan ditampilkan halaman petunjuk yang berisi cara menggunakan aplikasi dan keterangan fungsi tombol - tombol yang ada pada aplikasi. Setelah user paham dengan petunjuk aplikasi maka, user dapat kembali 


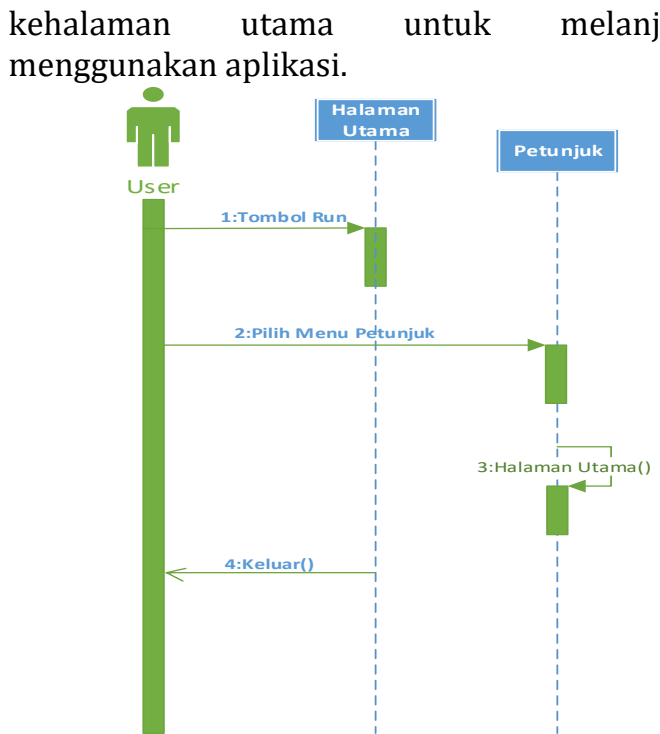

Gambar 3.8. Sequence diagram menu petunjuk

3) Diagram sequence pada menu Vehicles

Setelah user paham dengan cara menggunakan aplikasi, maka user dapat melanjutkan menggunakan menu belajar yang ada pada aplikasi. Menu belajar vehicle adalah salah satu menu belajar dengan materi nama nama alat transportasi, menu ini dijalankan dengan cara mengklik menu vehicle pada menu belajar. Apabila user telah selesai menggunakan menu vehicle atau ingin menggunakan menu belajar yang lain, maka user harus kembali ke halaman menu belajar untuk memilih menu belajar yang lainnya.

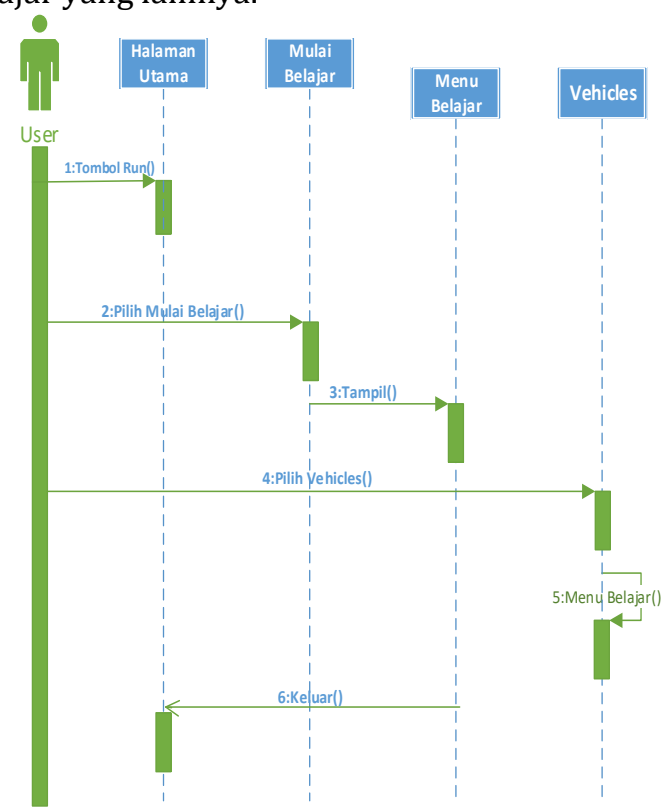

Gambar 3.9. Sequence diagram menu vehicles

\section{Implementasi dan Pembahasan \\ 5.1 Interface \\ 1) Interface Halaman Utama}

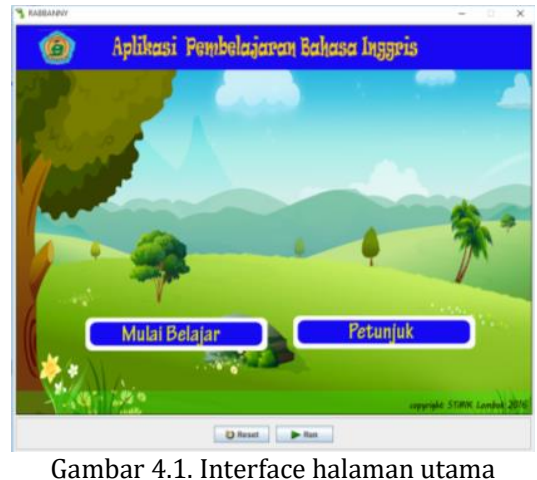

2) Interface Halaman Petunjuk

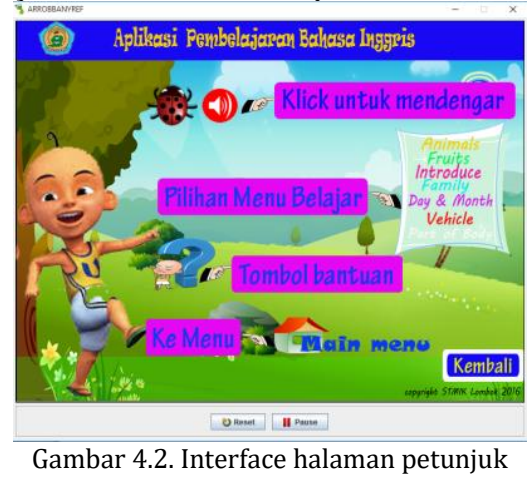

3) Interface Halaman Mulai Belajar

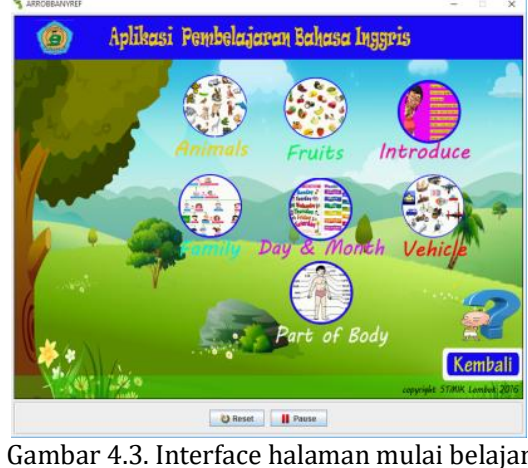

4) Interface Halaman Animals

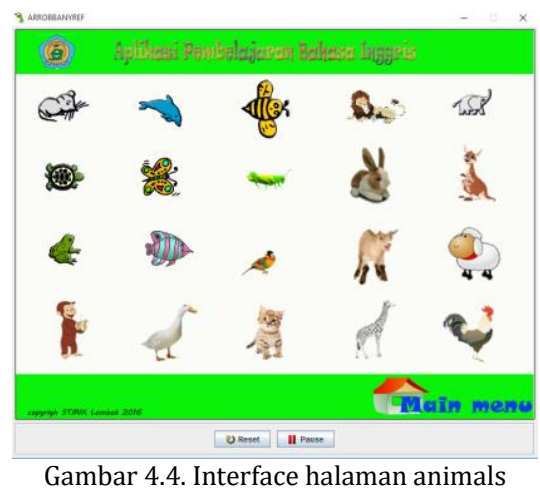




\subsection{Kompilasi Program}

Setelah selesai membuat program menggunakan aplikasi greenfoot maka langkah selanjutnya adalah mengkompile program agar dapat diakses langsung menggunakan aplikasi pembelajaran tanpa harus membuka program pendukungnya.

Format yang akan dihasilkan setelah melakukan kompilasi adalah fomat .jar, karena program greenfoot mendukung format .jar dan bukan .exe. sehingga sementara hanya dapat digunakan pada PC laptop.

Berikut langkah-langkah mengkompilasi program aplikasi pembelajaran bahasa inggris :

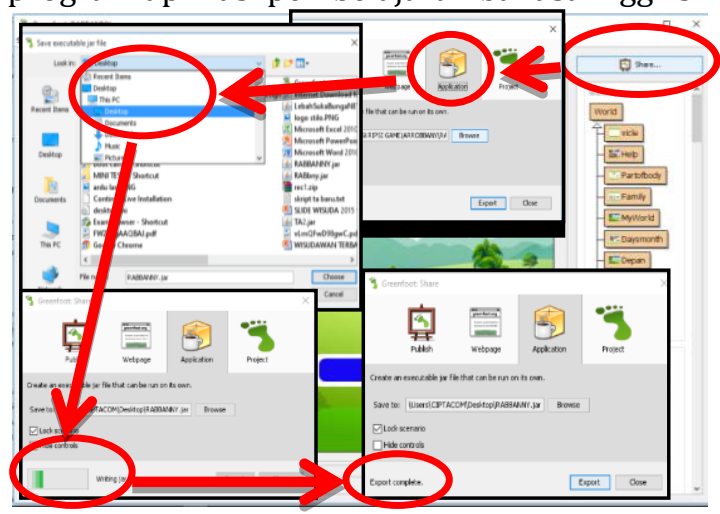

Gambar 4.5. Tahapan kompilasi aplikasi

\subsection{Black-box Testing}

Pengujian black-box adalah untuk mengetahui apakah fungsi perangkat lunak dalam pengoperasian aplikasi pembelajaran bahasa inggris ini dari input dan output data telah berjalan sesuai harapan pembuat. Hasil pengujian ditampilkan dalam bentuk tabel berikut:

Tabel 4.1. Hasil uji coba black-box menu utama

\begin{tabular}{|c|c|c|c|c|}
\hline $\begin{array}{l}\mathrm{N} \\
\mathrm{o}\end{array}$ & $\begin{array}{c}\text { Tombol } \\
\text { yang } \\
\text { Diuji } \\
\end{array}$ & Input & Output & $\begin{array}{l}\text { Kesimpu } \\
\text { lan }\end{array}$ \\
\hline 1 & Muabledeit & $\begin{array}{l}\text { Klik } \\
\text { tombol } \\
\text { menu } \\
\text { "Mulai } \\
\text { Belajar" }\end{array}$ & $\begin{array}{l}\text { Halaman } \\
\text { Mulai } \\
\text { Belajar }\end{array}$ & $\begin{array}{l}\text { Tampil } \\
{[\sqrt{]}}\end{array}$ \\
\hline 2 & Peturidu & $\begin{array}{l}\text { Klik } \\
\text { tombol } \\
\text { menu } \\
\text { "Petunjuk" }\end{array}$ & $\begin{array}{l}\text { Halaman } \\
\text { Petunjuk }\end{array}$ & $\begin{array}{l}\text { Tampil } \\
{[\sqrt{ }]}\end{array}$ \\
\hline
\end{tabular}

Pada tabel 4.1. merupakan hasil pengujian dari halaman menu utama yang berfungsi dengan baik.
Tabel 4.2. Hasil uji coba black-box halaman petunjuk

\begin{tabular}{|c|l|l|l|l|}
\hline $\begin{array}{c}\mathrm{N} \\
\mathrm{o}\end{array}$ & $\begin{array}{l}\text { Tombol } \\
\text { yang } \\
\text { Diuji }\end{array}$ & Input & Output & $\begin{array}{l}\text { Kesimpu } \\
\text { lan }\end{array}$ \\
\cline { 1 - 4 }$\cdot 1$ & Kembali & $\begin{array}{l}\text { Klik } \\
\text { tombol } \\
\text { menu } \\
\text { "Kembal } \\
\text { i" }\end{array}$ & $\begin{array}{l}\text { Kembali } \\
\text { ke menu } \\
\text { utama }\end{array}$ & $\begin{array}{l}\text { Tampil } \\
{[\sqrt{ }]}\end{array}$ \\
& & & \\
\hline
\end{tabular}

Pada tabel 4.2. merupakan hasil pengujian pada halaman menu petunjuk, dan tombol yang di uji adalah tombol kembali ke menu utama dan berjalan dengan baik.

Tabel 4.3. Hasil uji coba black-box mulai belajar

\begin{tabular}{|c|c|c|c|c|}
\hline $\begin{array}{l}\mathrm{N} \\
\mathrm{O}\end{array}$ & $\begin{array}{l}\text { Tombol } \\
\text { yang } \\
\text { Diuji } \\
\end{array}$ & Input & Output & $\begin{array}{l}\text { Kesim } \\
\text { pulan }\end{array}$ \\
\hline 1. & $\begin{array}{l}\text { Tombol } \\
\text { Vehicle }\end{array}$ & $\begin{array}{l}\text { Klik } \\
\text { tombol } \\
\text { "Vehicle" }\end{array}$ & $\begin{array}{l}\text { Halaman } \\
\text { vehicle }\end{array}$ & $\begin{array}{l}\text { Tampil } \\
{[\sqrt{]}}\end{array}$ \\
\hline 2. & $\begin{array}{l}\text { Tombol } \\
\text { Days } \\
\text { and } \\
\text { Months }\end{array}$ & $\begin{array}{l}\text { Klik } \\
\text { tombol } \\
\text { menu } \\
\text { "Days and } \\
\text { Months" }\end{array}$ & $\begin{array}{l}\text { Halaman } \\
\text { Days and } \\
\text { months }\end{array}$ & $\begin{array}{l}\text { Tampil } \\
{[\sqrt{]}}\end{array}$ \\
\hline 3. & $\begin{array}{l}\text { Tombol } \\
\text { Introdu } \\
\text { ce }\end{array}$ & $\begin{array}{l}\text { Klik } \\
\text { tombol } \\
\text { menu } \\
\text { "Introduce } \\
\text { " }\end{array}$ & $\begin{array}{l}\text { Halaman } \\
\text { Introduc } \\
e\end{array}$ & $\begin{array}{l}\text { Tampil } \\
{[\sqrt{]}}\end{array}$ \\
\hline 4. & 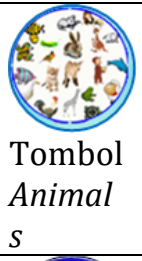 & $\begin{array}{l}\text { Klik } \\
\text { tombol } \\
\text { menu } \\
\text { "Animals" }\end{array}$ & $\begin{array}{l}\text { Halaman } \\
\text { Animals }\end{array}$ & $\begin{array}{l}\text { Tampil } \\
{[\sqrt{]}}\end{array}$ \\
\hline 5. & $\begin{array}{l}\text { Tombol } \\
\text { Part of } \\
\text { Our } \\
\text { Body }\end{array}$ & $\begin{array}{l}\text { Klik } \\
\text { tombol } \\
\text { menu } \\
\text { "Part of } \\
\text { Our Body" }\end{array}$ & $\begin{array}{l}\text { Halaman } \\
\text { Part Of } \\
\text { Our Body }\end{array}$ & $\begin{array}{l}\text { Tampil } \\
{[\sqrt{]}}\end{array}$ \\
\hline 6. & 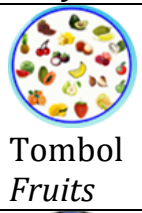 & $\begin{array}{l}\text { Klik } \\
\text { tombol } \\
\text { menu } \\
\text { "Fruits" }\end{array}$ & $\begin{array}{l}\text { Halaman } \\
\text { Fruits }\end{array}$ & $\begin{array}{l}\text { Tampil } \\
{[\sqrt{]}}\end{array}$ \\
\hline 7. & 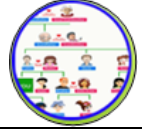 & $\begin{array}{l}\text { Klik } \\
\text { tombol } \\
\text { menu }\end{array}$ & $\begin{array}{l}\text { Halaman } \\
\text { Family }\end{array}$ & $\begin{array}{l}\text { Tampil } \\
{[\sqrt{]}}\end{array}$ \\
\hline
\end{tabular}




\begin{tabular}{|c|l|l|l|l|}
\hline & $\begin{array}{l}\text { Tombol } \\
\text { Family }\end{array}$ & "Family" & & \\
\hline 8. & $\begin{array}{l}\text { Klik } \\
\text { Tombol } \\
\text { Petunju } \\
\text { kombol"Pe } \\
\text { tunjuk" }\end{array}$ & $\begin{array}{l}\text { Buka } \\
\text { halaman } \\
\text { Petunjuk }\end{array}$ & $\begin{array}{l}\text { Tampil } \\
{[\sqrt{]}}\end{array}$ \\
\hline 9. & Kembali & $\begin{array}{l}\text { Klik } \\
\text { tombol } \\
\text { menu } \\
\text { "Kembali" }\end{array}$ & $\begin{array}{l}\text { Kembali } \\
\text { ke menu } \\
\text { utama }\end{array}$ & $\begin{array}{l}\text { Tampil } \\
{[\sqrt{]}}\end{array}$ \\
\hline
\end{tabular}

Pada tabel 4.3. merupakan hasil pengujian pada halaman menu Mulai Belajar, dan tombol yang di uji adalah tombol menu Vehicle, Days and Months, Introduce, Animals, Part of Our Body, Fruits, Family, Petunjuk, dan Kembali ke menu utama dan berjalan dengan baik.

Tabel 4.4. Hasil uji coba black-box halaman vehicle

\begin{tabular}{|l|l|l|l|l|}
\hline $\begin{array}{l}\mathrm{N} \\
\mathrm{O}\end{array}$ & $\begin{array}{l}\text { Tombol } \\
\text { yang Diuji }\end{array}$ & Input & Output & $\begin{array}{l}\text { Kesimpu } \\
\text { lan }\end{array}$ \\
\hline 1. & & Klik & Kemba & Tampil \\
& tomb & $\begin{array}{l}\text { li ke } \\
\text { li } \sqrt{ }] \\
\end{array}$ & & ol menu \\
& & "main menu & Mulai & \\
& & menu & Belajar & \\
& & & \\
\hline
\end{tabular}

Pada tabel 4.4. merupakan pengujian pada halaman menu Vehicle, dimana tombol main menu untuk kembali ke halaman menu Mulai Belajar dapat berjalan dengan baik.

\subsection{Quesioner Penggunaan Aplikasi}

Pengujian Aplikasi Pembelajaran Bahasa Inggris ini menggunakan kuisioner dengan responden 23 siswa dari kelas basic laki-laki pada Lembaga Kursus Bahasa Inggris Arrobbany. Pengujian dilakukan dengan memakai 3 pernyataan dari kuisioner yang diisi oleh tutor berdasarkan pengamatan kepada masing-masing siswa.

Berikut ini adalah hasil persentase yang diperoleh dari responden yang sudah dihitung nilainya.

Tabel 4.5. Tabel aspek penilaian

\begin{tabular}{|l|l|c|}
\hline \multirow{2}{*}{ NO } & \multicolumn{3}{|c|}{ PEabel 4.5. Tabel aspek penilaian } \\
\cline { 2 - 4 } & PSPEK YANG DINILAI & PERSENTASE \\
\hline 1 & $\begin{array}{l}\text { Minat siswa untuk } \\
\text { menggunakan aplikasi } \\
\text { pembelajaran bahasa } \\
\text { inggris }\end{array}$ & $74 \%$ \\
\hline
\end{tabular}

\begin{tabular}{|l|l|l|}
\hline 2 & $\begin{array}{l}\text { Aplikasi pembelajaran } \\
\text { bahasa inggris } \\
\text { menghasilkan suara } \\
\text { yang tepat dengan } \\
\text { objek yang ada }\end{array}$ & $100 \%$ \\
\hline 3 & $\begin{array}{l}\text { Aplikasi pembelajaran } \\
\text { bahasa inggris dapat } \\
\text { menggantikan native } \\
\text { speaker }\end{array}$ \\
\hline
\end{tabular}

\section{Penutup}

\subsection{Kesimpulan}

1. Aplikasi Pembelajaran Bahasa Inggris ini dirancangan dengan metode UML(Unified Modelling Language), desain interface menggunakan Photoshop, pengambilan suara asli atau native speaker dari Google Translation serta dibangun menggunakan aplikasi Greenfot versi 3.0.4. dengan bahasa pemrograman java.

2. Berdasarkan pengujian kepada 23 siswa, menunjukkan bahwa aplikasi pembelajaran ini menarik minat belajar siswa, melatih siswa mengucapkan kata dalam bahasa inggris dan dapat menggantikan peran native speaker. Hal ini dibuktikan dengan persentase penilaian rata-rata yang diperoleh yaitu $82 \%$.

\subsection{Saran}

Aplikasi pembelajaran yang sudah dibuat sudah berjalan dengan baik sesuai dengan tujuan awal dari penelitian ini. Adapun saran untuk pengembangan pada aplikasi pembelajaran bahasa inggris ini yaitu :

1. Sebaiknya aplikasi ini dibuat installer dalam bentuk *.exe dan berbasis android, sehingga tidak hanya digunakan di PC tetapi dapat juga menggunakan smartphone.

2. Pada aplikasi pembelajaran bahasa inggris ini perlu ditambahkan halaman Quis untuk mengukur kemampuan siswa dalam materi pronunciation.

3. Pada aplikasi pembelajaran bahasa inggris ini perlu ditambahkan materi dan image yang lebih bervariasi dari luar aplikasi tidak hanya menggunakan image yang ada pada greenfoot. 


\section{Daftar Pustaka :}

Dewi Ghea Putri Fatma.(2012). Pengembangan Game Edukasi Pengenalan Nama Hewan Dalam Bahasa Inggris Sebagai Media Pembelajaran Siswa SD Berbasis Macromedia Flash.Skripsi TI.Hlm.1-16

Gautama, R. S., \& Kasih I. (2013). Rancang Bangun Aplikasi Pembelajaran Bahasa Inggris Berbasis Multimedia Pada Bimbel Excellence. Naskah Publikasi TI. Hlm.1-10.

Hong Cen.(2012). Perancangan dan Pengembangan Game Multiplayer untuk Pelatihan Pengucapan Bahasa Inggris Berbasis Android. Disertasi Doktoral TI.HIm.1-21

Hodia, Maelani, and Khairul Imtihan-STMIK Lombok. "Perancangan Sistem Informasi Praktek Klinik Kebidanan (PKK) Pada Prodi DIII Kebidanan Stikes Qamarul Huda." IJNS-Indonesian Journal on Networking and Security 6.3 (2017).

Kurniasari Yessy.(2013). Perancangan Permainan Mengasah Daya Ingat "Memory Training" Menggunakan Greenfoot. Makalah Seminar TA. Hlm. 1-7.

Khairul Imtihan. "Perencanaan Strategi Sistem Informasi Pendidikan Pada Sekolah Tinggi Manajemen Informatika dan Komputer (STMIK) Lombok." Bianglala Informatika 3.2 (2015).
Nugroho Septyanto Jati. (2015). Aplikasi Pembelajaran Bahasa Inggris untuk Anak SD Menggunakan Construct 2. Naskah Publikasi TI. Hlm. 1-20.

Priambodho Galih Dadag. (2016). Aplikasi Game Edukasi Pelafalan Huruf Alphabet Berbasis Android. Skripsi TI. HIm. 1-10.

Suswanti.(2015).Pembuatan Game Berbasis Android Menangkap Belalang untuk Melatih Kecermatan dan Ketajaman Berpikir Anak.Naskah Publikasi TI. HIm.16

Susilawati, Sita, and Maulana Ashari. "Perancangan Jaringan Closed Circuit Television (CCTV) Berbasis Online Sebagai Monitoring Pada SDN 4 Praya." Jurnal Manajemen Informatika dan Sistem Informasi 1.1 (2018): 11-16.

Sri Dharwiyanti. dan Romi Satria Wahono.(2013). Pengantar Unified Modelling Language(UML).

http://www.IlmuKomputer.net diakses tanggal 23 Nopember 2016

Zaen, M. Taufan Asri, Sunaryo Sunaryo, and Wijono Wijono. "Sistem Pendukung Keputusan untuk Investasi Perumahan Area Malang Menggunakan P Algoritma Bayesian." Jurnal EECCIS 8.1 (2014): 1318.

www.greenfoot.org 